\title{
Médiévales
}

Langues, Textes, Histoire

78 | printemps 2020

Moyen Âge en séries

Nicolas Weill-Parot, Véronique Sales, Le Vrai Visage du Moyen Âge. Au-delà des idées reçues

Paris, Vendémiaire («Retour au Moyen Âge »), 2017, 415 p.

\section{Marie Delcourte-Debarre}

\section{OpenEdition}

\section{Journals}

Édition électronique

URL : https://journals.openedition.org/medievales/11012

DOI : 10.4000/medievales. 11012

ISSN : 1777-5892

\section{Éditeur}

Presses universitaires de Vincennes

Édition imprimée

Date de publication : 20 août 2020

Pagination : 229-231

ISBN : 978-2-37924-093-5

ISSN : 0751-2708

\section{Référence électronique}

Marie Delcourte-Debarre, « Nicolas Weill-Parot, Véronique Sales, Le Vrai Visage du Moyen Âge. Au-delà des idées reçues », Médiévales [En ligne], 78 I printemps 2020, mis en ligne le 09 novembre 2020, consulté le 24 avril 2022. URL : http://journals.openedition.org/medievales/11012 ; DOI : https:// doi.org/10.4000/medievales. 11012

Ce document a été généré automatiquement le 24 avril 2022

Tous droits réservés 


\title{
Nicolas Weill-Parot, Véronique Sales, Le Vrai Visage du Moyen Âge. Au-delà des idées reçues
}

Paris, Vendémiaire («Retour au Moyen Âge »), 2017, 415 p.

\author{
Marie Delcourte-Debarre
}

\section{RÉFÉRENCE}

Nicolas Weill-Parot, Véronique Sales, Le Vrai Visage du Moyen Âge. Au-delà des idées reçues, Paris, Vendémiaire («Retour au Moyen Âge »), 2017, 415 p.

1 Ce recueil collectif est dirigé par Nicolas Weill-Parot, historien médiéviste des sciences, et Véronique Sales, fondatrice de la maison d'édition Vendémiaire et auparavant rédactrice en chef adjointe du magazine L'Histoire. Cette affiliation pourrait expliquer le format de l'ouvrage: des entretiens sous forme de questions-réponses avec un spécialiste des thèmes abordés.

2 Il regroupe vingt-deux contributeurs et est destiné à un large public. Il se propose de déconstruire les idées reçues - anciennes et nouvelles - sur le Moyen Âge ${ }^{1}$. La démarche est explicitée dans une brève introduction: décrire les idées fausses, rétablir une «forme d'exactitude historique» (p. 7), expliquer la genèse de ces dernières et leurs temporalités. Philippe Contamine rappelle d'ailleurs que l'Histoire doit être rattachée à la réalité afin d'« informer, éclairer, faire réfléchir» (p. 9). Nous soulignons l'important travail de coordination et de relecture nécessaire à la réalisation de ce recueil, formant « un podcast écrit » sans aucune redite et particulièrement accessible au grand public.

De taille variable, les vingt-cinq articles ne sont regroupés ni selon un axe séquentiel ni de manière thématique. Le fil conducteur qui les organise semble être celui de l'association d'idées. Par exemple, l'article de Boris Bove, «La ville: cloaque et forteresse ", est suivi de la réflexion de Marilyn Nicoud sur l'hygiène au Moyen Âge. Chaque article est accompagné d'une dizaine de références bibliographiques, situées 
dans une bibliographie indicative en fin d'ouvrage qui permet aux lecteurs d'approfondir les investigations. Cette courte bibliographie par article comprend à la fois les travaux classiques de référence et des ouvrages récents en français et en langue étrangère.

Les contributions sur l'Occident chrétien sont majoritaires (la France en premier lieu, quelques mentions de l'Italie, de l'Angleterre, de l'Écosse, etc.). Nous soulignons le remarquable changement d'échelles opéré dans cet ouvrage, du national (Philippe Contamine, Franck Collard, Colette Beaune) à une histoire mondiale (Patrick Gautier Dalché, Jacques Paviot). L'espace urbain est le cadre privilégié d'étude pour bon nombre de contributions (Jacques Verger, Boris Bove, etc.). Cependant, nous regrettons qu'il n'y en ait pas davantage sur les campagnes médiévales. La contribution de Nicolas Carrier sur la question du servage est d'ailleurs la seule à porter sur l'économie médiévale.

5 L'ouvrage a été conçu afin d'« ouvrir les portes d'entrée sur de multiples aspects du Moyen Âge » (p. 7). C'est ainsi que de nombreux thèmes sont abordés : la découverte du monde, les alchimistes, les innovations techniques, l'hygiène, la science, l'université, la médecine, la traduction, le droit de cuissage, le serf, le chevalier, la femme, etc. D'autres thématiques, plus connues du grand public, sont souvent celles qui véhiculent le plus d'idées reçues, comme : Jeanne d'Arc, les templiers, les croisades, les hérétiques, l'inquisition, la sorcellerie.

6 Huit planches d'illustrations en couleurs sont présentes au milieu de l'ouvrage, organisées par thème: travaux des champs, commerce et arts, chevalerie et amour courtois, croisades, alchimistes et médecins, imaginer le monde et, enfin, pèlerinage. Elles forment un instrument intéressant de visualisation pour le grand public. Mais il aurait été utile d'y intégrer une carte de localisation des différents cas d'étude afin que le lecteur puisse se repérer spatialement.

7 L'ouvrage est un bel outil de diffusion des acquis de la recherche médiévale actuelle. Les contributions forment une voie d'entrée dans la période, en replaçant les mythes dans leur contexte de création. Ainsi, les différents auteurs insistent sur l'origine et la temporalité des idées reçues sur la période, qu'elles soient défavorables ou idéalisées. Au cœur du Moyen Âge, le mythe de Jeanne d'Arc, à la fois sorcière et sainte, débute dès son procès (C. Beaune). Dominique Barthélémy rappelle, quant à lui, que la vision idéalisée de la chevalerie s'est constituée dès les $\mathrm{XI}^{\mathrm{e}}$-XIII ${ }^{\mathrm{e}}$ siècles. Au XVIII ${ }^{\mathrm{e}}$ siècle, les savants débattent sur la rotondité de la terre (P. Gautier Dalché). C'est à cette même période, que le mythe de la tolérance andalouse voit le jour, suite à la découverte de la dhimma musulmane que l'on a assimilée "à la tolérance chrétienne, voltairienne " (Gabriel Martinez-Gros, p. 83). Quant au XIXe siècle, le catharisme est perçu comme une religion «alternative » dans le midi de la France (André Vauchez, p. 177), tandis que les écrits érudits sur le droit de cuissage se multiplient (Alain Boureau). Enfin au XX ${ }^{\mathrm{e}}$ siècle, le cinéma se réapproprie un imaginaire "médiévalisant " (Laurent Vissière, p. 47), sur lequel s'appuie l'heroic fantasy qui diffuse des images de la guerre médiévale inscrites dans l'imaginaire contemporain.

Valérie Toureille revient sur la notion de violence véhiculée par les séries et les films actuels, et rappelle l'importance de nuancer les codes de la justice médiévale en fonction des sources disponibles (ordre public, torture, justice barbare, etc.). L'inquisition véhicule elle aussi des présupposés. Dans son étude, A. Vauchez redéfinit le mot "hérétique» en prenant l'exemple des cathares, et évoque les avancées de l'historiographie actuelle, notamment par la notion de déconstructivisme : il s'agit de 
savoir «si l'hérésie a réellement existé au Moyen Âge et si elle n'est pas une invention de l'Église » (p. 190). Certains ont tenté d'établir un lien entre les cathares et l'ordre du Temple, ce qui n'est qu'une des idées reçues relatives aux Templiers. Dans son entretien, Philippe Josserand rappelle l'origine de ces idées et les déconstruit.

Les différentes contributions sont d'une grande rigueur scientifique et offrent des bilans notamment historiographiques, pertinents et accessibles (Didier Kahn sur « L'âge d'or des alchimistes », Nicolas Weill-Parot sur «Magie, sorcellerie et science »). C'est ainsi que G. Martinez-Gros rappelle que les croisades n'ont pas été un événement capital dans l'histoire de l'Islam, que la connaissance du monde musulman - du monde plus généralement - s'est accrue entre la fin du $\mathrm{XI}^{\mathrm{e}}$ et le $\mathrm{XIII}^{\mathrm{e}}$ siècle. Les apports de Catherine Verna, Jacques Verger et Danielle Jacquart rappellent l'ouverture du monde médiéval et cette nécessaire mise en contact, tant d'un point de vue technique qu'intellectuel, tout en explicitant les codes socioculturels de l'époque, comme par exemple l'exclusion des femmes du monde universitaire (Valérie Toureille).

La contribution de Frank Collard sur le roman national fait suite à la réflexion de P. Contamine sur la position du royaume de France en tant qu'État-Nation. Elle réalise une synthèse définissant le roman national tout en le mettant en lien avec l'histoiremonde. L'exposé de Jacques Paviot revient sur les courants historiographiques actuels de la World History ou de l'histoire connectée en revenant sur la notion de voyage au Moyen Âge et le rapport à l'inconnu, à l'étranger. L'auteur rappelle par ailleurs que l'Amérique a été découverte bien avant Christophe Colomb.

11 Enfin, le recueil se termine par une contribution de Boris Bove qui déconstruit l'image négative du Moyen Âge, «Le temps des malheurs : la peste, la faim, la guerre » (p. 373). L'auteur interroge l'idée d'une crise systémique de la fin du Moyen Âge en vulgarisant les résultats qu'il présente dans son volume de la collection «L'Histoire de France » intitulé Le Temps de la guerre de Cent Ans (Belin, 2009).

12 En conclusion, Le Vrai Visage du Moyen Âge tient ses promesses tout en étant accessible au grand public. Il débarrasse le «visage du Moyen Âge» des présupposés qui le couvre. Montrant que cette période est une phase de progrès et de mutations profondes, il apparaît ainsi comme un véritable ouvrage de référence.

\section{NOTES}

1. Notons qu'un autre ouvrage collectif paru également en 2017 se propose de reconsidérer les représentations négatives sur le Moyen Âge : F. Besson, P. Guéna, C. Kikuchi, A. Marin éd., L'Actuel Moyen Âge, Paris, 2017. 


\section{AUTEURS}

\section{MARIE DELCOURTE-DEBARRE}

Université Polytechnique Hauts-de-France 